\title{
Darwin na Escola: Relato de Uma Experiência de Divulgação Científica
}

\author{
Biological Evolution In School: An Experience Of \\ Communication And Dissemination Of Scientific Culture
}

\section{RESUMO}

O objetivo deste artigo é relatar as experiências de um projeto de extensão que buscou estimular o interesse de estudantes do ensino médio pela teoria da evolução biológica, popularizando os conceitos-chave das ideias promulgadas por Charles Darwin (1859). As ações do projeto foram: (1) conhecer, por meio da aplicação de questionários, a percepção que estudantes do ensino médio e seus professores de Biologia apresentam sobre ciência e a teoria da evolução biológica; (2) promover mostras científicas por meio da oferta de oficinas e minicursos nas escolas públicas. Os resultados indicam que as percepções dos estudantes e professores do Ensino Básico, em relação à ciência e à teoria da evolução biológica, são otimistas e positivas, e as crenças pessoais não parecem influenciar em seus posicionamentos sobre o tema. $\mathrm{O}$ estudo das percepções de estudantes e professores forneceu subsídios na definição de "o que, para quem e como comunicar” temas científicos no espaço escolar. Assim, seguiu-se a segunda etapa deste projeto - a elaboração e execução de oficinas para estudantes do ensino básico - que resultou em novas oportunidades, para os envolvidos, de reconstruir a relação e atribuir valores a ciência.

Palavras-chave: Cultura Científica. Divulgação. Educação Científica. Evolução Biológica.

\section{ABSTRACT}

The objective of this paper is to report the experiences of an extension project that aimed to stimulate the interest of high school students by the theory of biological evolution, popularizing the key concepts of the ideas promulgated by Charles Darwin (1859). The project's actions were: (1) known, by means of questionnaires, the perception that high school students and their biology teachers have on science and the theory of biological evolution; (2) promote science exhibitions by offering

Graciela da Silva

\section{OliveIRA}

Universidade Federal do Mato Grosso. Instituto de Biociências, Mato Grosso, Brasil 
workshops and short courses in public schools. The results indicate that the perceptions of students and teachers of basic education in relation to science and theory of biological evolution, are optimistic and positive, and personal beliefs do not seem to influence in their positions on the subject. The study of the perceptions of students and teachers provided information on the definition of "what, for whom and how to communicate" scientific subjects at school. So was followed by the second stage of this project - the development and implementation of workshops for students of basic education - which resulted in new opportunities for those involved, to rebuild the relationship and assign values to science.

Keywords: Scientific Culture. Disclosure. Science Education. Biological Evolution.

\section{INTRODUÇÃO}

Este artigo tem como objetivo relatar as experiências de ensino, pesquisa e extensão vivenciadas durante o desenvolvimento do Projeto de Extensão Evolução Biológica: exposições científicas e culturais nas escolas públicas de Cuiabá - MT, realizado entre os anos de 2011-2012 por um grupo de estudantes e sua professora, durante o curso de Licenciatura em Ciências Biológicas. Esse projeto de extensão teve como enfoque estimular o interesse dos estudantes de ensino médio pela teoria da evolução biológica, popularizando os conceitos-chave das ideias promulgadas por Charles Darwin (1859), bem como os conceitos científicos das Ciências Biológicas que estão diretamente ligados a essas ideias.

O desenvolvimento desse projeto de extensão foi importante, de modo amplo, para aproximar o público acadêmico e o escolar em um processo de comunicação científica e, particularmente, contribuiu para ampliar a compreensão da percepção pública de jovens estudantes e professores da educação básica sobre a ciência, apontando caminhos para ações mais efetivas de desenvolvimento de uma cultura científica.

Quando se fala em cultura científica, alguns desafios merecem destaque, pois de acordo com Vogt [15] nunca na história houve tantas iniciativas governamentais e acadêmicas em favor da comunicação científica e tecnológica no mundo. Porém, embora sejam várias as iniciativas e as razões em favor da divulgação e comunicação científica, paradoxalmente, nota-se um declínio de jovens interessados em assuntos relacionados à ciência, bem como em seguir uma carreira científica, apesar de conviverem intensamente com produtos científicos e tecnológicos.

As razões que afastam os jovens de temas científicos parecem associadas, principalmente, as suas experiências e valores adquiridos durante a sua trajetória escolar. Vogt [15] explica sobre essa associação:

a palavra "ciência" assusta a esmagadora maioria dos cidadãos [...] porque traz à memória fracassos escolares por incapacidade de compreensão ou de manipulação de conceitos. Com demasiada frequência, o ensino das ciências funciona como um fator de seleção dos “bons” e de exclusão dos “maus”. Depois, logicamente, slogans como "a ciência é divertida, criativa e ao alcance de todos”... parecem mentiras. 
Dessa forma, durante o projeto buscou-se adotar formas mais amplas e coerentes de comunicação científica, de maneira que decorresse um trabalho conjunto entre todos os membros envolvidos. As ações foram articuladas em função do desenvolvimento do ensino, da pesquisa e da extensão universitária, para as quais se previu a participação dos estudantes de Ciências Biológicas desde o planejamento até a realização nas escolas de educação básica, onde também se envolveram os professores e os estudantes. Assim, as ações implementadas foram: (1) conhecer a percepção dos estudantes do ensino médio e seus professores de Biologia sobre ciência a partir das atitudes diante da teoria da evolução biológica; (2) promover mostras científicas através de oficinas e minicursos nas escolas públicas.

Vogt e Castelfranchi [14] comentam que as maneiras que os indivíduos percebem e utilizam o conhecimento científico articula-se em função da compressão do conteúdo de ciências associados a contextos mais amplos de informações, como atitudes, opiniões e valores atribuídos a ele. Consequentemente, os objetivos de difusão da ciência escolar podem ser reestruturados a partir de um plano sociocultural de construção e aproximação da população aos conhecimentos científicos.

Desta forma, consideramos que projetos de divulgação científica apresentarão resultados mais efetivos quando a noção da ciência escolar romper com a visão de uma simples aquisição de conteúdos desconectados da realidade social dos jovens estudantes.

A opção pela teoria da evolução biológica como orientadora do projeto justifica-se, primeiramente, por apresentar papel chave na compreensão da dinâmica entre os seres vivos e o meio ambiente, bem como no processo de diversificação, sustentando noções chaves das Ciências Biológicas, como: seleção natural, adaptação e sobrevivência em um nicho ecológico. Esses princípios básicos do conhecimento biológico contribuem para a compreensão de questões cotidianas dos estudantes, como, por exemplo, a conservação da biodiversidade, as transformações ambientais, as consequências do uso indiscriminado de antibióticos, entre outros temas intimamente ligados à teoria evolutiva e que exigem a utilização de seus conceitos para a solução de problemas concretos, assim colaborando para o entendimento e a análise do meio ambiente.

Contudo, a teoria da evolução biológica é um tema considerado controverso, pois as atitudes relacionadas a ela frequentemente são influenciadas por ideias, memórias, experiências e concepções de evolução diferentes das estabelecidas pela ciência [1]. A esse respeito, Cobern [6] explica que as questões da teoria evolutiva e origens da vida apresentam a mais clara sobreposição entre ideias científicas e outras ideias da sociedade.

Por esses motivos, o desenvolvimento de pesquisas empíricas e de iniciativas de comunicação e divulgação científicas interessadas em entender e estabelecer relações entre educação científica e educação cultural é imprescindível para a compreensão dos diálogos entre ciência e cultura, presentes no ensino básico. 


\section{MATERIAIS E MÉTODOS}

Este projeto foi desenvolvido por uma professora e alunos do curso de Licenciatura em Ciências Biológicas, do Instituto de Biociências - Campus Cuiabá (MT) -, matriculados na disciplina Instrumentação para o Ensino III, sendo dois bolsistas de Extensão e outros 19 alunos da disciplina. O público alvo configurou-se em alunos dos três anos do ensino médio e seus respectivos professores de Biologia, de duas escolas públicas de Cuiabá, uma municipal e a outra estadual. A escolha dessas escolas deveu-se à proximidade da gestão do projeto com alguns de seus funcionários.

O total de alunos do ensino médio participantes do projeto foi de 227, cujas faixas etárias estão distribuídas da seguinte forma: menos de 15 anos, três alunos; entre $15 \mathrm{e}$ 20 anos, 189 alunos; e mais de 20 anos, 30 alunos. Não responderam a essa pergunta cinco alunos.

O Gráfico 1 mostra a distribuição desses alunos por ano de escolarização:

Gráfico 1- Distribuição dos jovens estudantes que participaram do projeto, por ano escolar

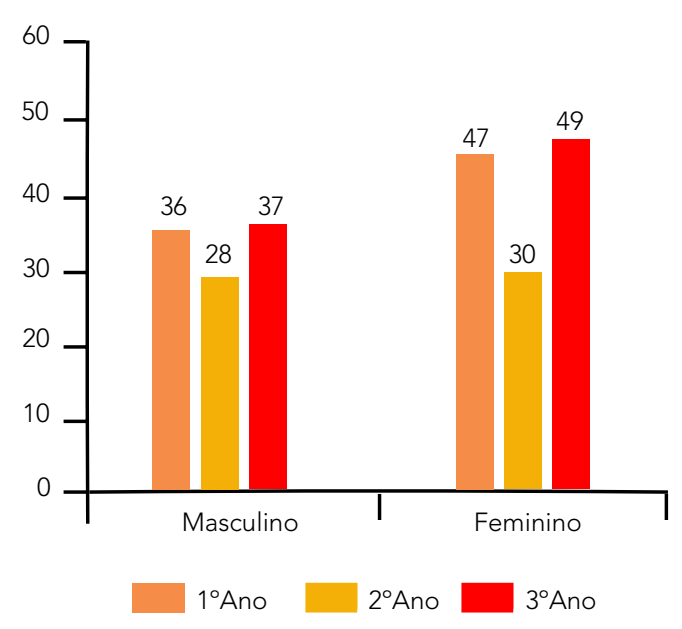

O desenvolvimento e implementação do projeto de extensão contou com a participação de três professoras da educação básica. Surgiu daí a necessidade de ampliar a aplicação do questionário percepção pública da evolução biológica para os professores de outras escolas públicas, ampliando assim o número de inquiridos para 17 professores, em oito escolas municipais e estaduais, sendo 16 do sexo feminino. Quanto à faixa etária desses docentes, delimita-se: 24 anos, um professor; 29 anos, dois professores; entre 30 e 39 anos, quatro professores; entre 40 e 48 anos, oito professores; e com 50 e 54 anos, dois professores.

Após a formação de equipe e a seleção dos estudantes extensionistas, foram realizados encontros semanais com a participação dos licenciandos e a professora responsável pelo projeto, para elaboração das ações e atividades que seriam desenvolvidas nas escolas. No entanto, o grupo ainda estava pequeno para abarcar o desenvolvimento das atividades previstas. Assim, os estudantes matriculados na disciplina de Instrumentação para o Ensino III foram convidados a participar das ações nas escolas $(\mathrm{N}=16)$. 
Inicialmente, todos os acadêmicos foram convidados a levantar as referências bibliográficas que iriam nortear os trabalhos do projeto de extensão e aprofundar os estudos sobre a teoria da Evolução Biológica. As leituras recomendadas inicialmente foram textos produzidos numa linguagem voltada ao professor da educação básica: Evolução: o sentido da biologia [7]; Darwin: do Telhado das Américas à Teoria da Evolução [3]; Evolução biológica: ensino e aprendizagem no cotidiano de sala de aula [11]. Após a síntese e fichamento dos materiais bibliográficos selecionados a equipe de trabalho iniciou a implementação das ações descritas a seguir.

Foram planejados encontros/reuniões com os professores das escolas, totalizando 20 horas, para estudos e discussões de temas relacionados à teoria da evolução biológica, com o objetivo de elaborar em conjunto as propostas de atividades que seriam oferecidas, bem como compor um grupo de estudos permanente sobre o ensino e aprendizagem da teoria da evolução biológica e as influências socioculturais. No entanto, não houve a implementação do grupo de estudos por dificuldades de conciliação dos horários para os encontros.

Assim, ao longo do trabalho, os graduandos visitaram as escolas para definir detalhes do projeto e optaram pela aplicação de um questionário para verificar as percepções dos professores sobre a teoria e o ensino da evolução biológica. Os questionários foram compostos por questões de múltipla escolha e em escala do tipo Likert de quatro pontos, para facilitar a recolha dos dados, de maneira que não interrompesse a rotina do professor.

A escala de Likert foi desenvolvida por Rensis Likert, em 1932, ao elaborar diferentes afirmações em vez de perguntas, foram atribuídos valores que representam a concordância ou discordância das afirmações. Likert propôs uma escala de cinco pontos com um ponto médio para registro da manifestação de situação intermediária de indiferença ou de nulidade, do tipo: (1) discordo totalmente; (2) discordo; (3) indeciso; (4) concordo; (5) concordo totalmente. Obtém-se um valor para cada pessoa e para cada item [9].

As questões presentes no questionário aplicado ao professor versavam sobre: caracterização socioeconômica; motivos/razões para o ingresso na carreira docente; proximidade com a ciência e com a evolução biológica; opinião a respeito do ensino da teoria da evolução biológica; e proximidade à religião. Para análise dos dados obtidos foi feita uma contagem de frequência simples, e os resultados foram representados em números absolutos, por se tratar de uma amostra pequena de inquiridos.

O questionário aplicado para os estudantes do ensino médio foi elaborado com base no estudo realizado por Oliveira e Bizzo [8] com auxílio do instrumento Relevance of Science Education (ROSE). O ROSE é um estudo internacional, elaborado pelo professor Svein Sjøberg e pesquisadores da Universidade de Oslo, que teve como objetivos: investigar opiniões de estudantes na faixa etária dos 15 anos de idade sobre suas experiências nas aulas de ciências e sua relação com ciência em geral e com a carreira científica. Esse projeto foi adaptado por pesquisadores de diferentes países, e seu instrumento de coleta de dados - um questionário fechado com 245 itens, em escala do tipo Likert de quatro pontos - já foi aplicado em mais de 40 países [12]. 
A coleta dos dados foi realizada a partir do contato direto com os inquiridos, durante o período letivo, em horários previamente negociados com a gestão e com os professores da escola. A aplicação dos questionários durava, em média, 20 minutos.

As questões presentes nos questionários aplicados aos estudantes versavam sobre: caracterização socioeconômica; proximidade e interesse por ciências e suas aulas de ciências; interesse por tópicos que sustentam a teoria da evolução biológica; e caracterização cultural, particularmente, proximidade com crenças religiosas. A escolha dos temas ciência e religião foram importantes para compreensão de como os estudantes se relacionam com eles.

Os dados obtidos foram processados no Software Statistical Package for Social Science (SPSS) - Pacote Estatístico para as Ciências Sociais - versão 18.o, que é um programa estatístico facilitador e mediador do trabalho de análise numérica. O SPSS utilizado foi licenciado pelo projeto Desempenho escolar inclusivo na perspectiva multidisciplinar - Observatório da Educação (CAPES/INEP, 2010), no qual a coordenadora do presente projeto participa como pesquisadora.

Para avaliar diferenças entre as amostras e relações entre as variáveis, foram realizadas análises descritivas de frequências absolutas e relativas, seguidas do exame das variáveis e suas correlações por análises multivariadas (Mann Whitney e Kruskal-Wallis).

À luz dos referenciais teóricos que orientam o ensino da teoria da evolução biológica, os acadêmicos elaboraram oficinas pedagógicas para aplicação nas escolas, com base em um roteiro denominado Oficina Pedagógica, no qual caracterizaram: carga horária; limite de vagas; ementa; objetivos educacionais; materiais necessários; sistemática/desenvolvimento do trabalho; e estratégias de avaliação e autoavaliação.

A duração de cada oficina foi de quatro a oito horas e essas formações versaram sobre temas relacionados à teoria da evolução biológica. Para chamar atenção dos jovens, as oficinas receberam os seguintes títulos: Evolução Biológica: afinal o que é isso?; A natureza: entre o bem e o mal; Répteis: descobrindo seu passado; $O$ que os olhos não veem; Quem é Darwin?; e Os fósseis e você, tudo a ver.

Ao final das oficinas, o grupo de pesquisadores avaliou as opiniões dos estudantes sobre as atividades que foram desenvolvidas e retomou, também, as ideias iniciais que os jovens apresentaram sobre ciência e evolução biológica.

\section{COMUNICAÇÃO E DIFUSÃO DA CULTURA CIENTÍFICA ATRAVÉS DA TEORIA DA EVOLUÇÃO BIOLÓGICA}

O projeto teve início com a busca pela percepção sobre ciência entre os jovens matriculados no ensino médio e seus professores de Biologia.

Quanto à percepção que os estudantes têm sobre ciência, não houve diferença estatística significativa ao nível de $5 \%$ nas respostas dos estudantes quanto às variáveis: sexo, idade e série.

Os dados obtidos indicam que os jovens consideram que a ciência é relevante para a sociedade e contribui para resolver problemas do cotidiano. Paradoxalmente, 
quando esses jovens são questionados sobre o interesse de seguir uma carreira científica ou trabalhar com algum tipo de tecnologia, os níveis de concordância são menores.

Resultados semelhantes foram encontrados por Santos Gouw [10]. A autora destaca que os jovens brasileiros têm uma atitude, em geral, otimista em relação à Ciência e Tecnologia (C\&T), e a consideram responsável não só pela cura de doenças, mas também por melhores oportunidades futuras e pelo desenvolvimento adequado de um país. Assim, os jovens atribuem à $C \& T$ a possibilidade de uma vida mais saudável, fácil e confortável. A pesquisadora ainda chama a atenção para os altos índices de otimismo ou valorização da ciência entre os jovens das regiões Centro-Oeste, Norte e Nordeste. Por outro lado, os informantes do Sul e Sudeste pareceram menos empolgados e mais críticos em relação ao papel da C\&T na sociedade.

Ao se comparar os dados encontrados na pesquisa apresentada neste artigo com a amostra nacional de Santos Gouw [10], depreende-se que a juventude do Centro-Oeste apresenta maior interesse pela C\&T do que os estudantes de outras regiões do país. No entanto, para caracterizar as opiniões dos jovens cuiabanos, é necessária a ampliação desta pesquisa para uma amostra representativa dos estudantes de Cuiabá, tendo como referência um cuidadoso planejamento amostral que possibilite documentar o conjunto de atitudes e interesses, bem como a relação do jovem com a $\mathrm{C} \& \mathrm{~T}$, levando em conta o perfil socioeconômico e cultural e os contextos escolares dos informantes.

Quanto à opinião dos jovens a respeito da teoria da evolução biológica, foram respondidas duas questões, a primeira sobre a base científica e a credibilidade atribuída à teoria, e a segunda, sobre a aceitação de tópicos que sustentem a teoria da evolução biológica.

De maneira geral, os jovens concordaram que a teoria da evolução biológica é um tema aceito entre os cientistas e resultado de estudos científicos sólidos. No entanto, quando é abordada a diferença entre o discurso religioso e o discurso científico, $51,6 \%$ dos jovens discordam de que "a teoria da evolução está correta, mesmo não concordando com o relato bíblico da criação”* Ressalta-se que $16,7 \%$ deles não responderam a esse item. Esses altos índices de abstenção e discordância podem sugerir um desconforto entre os jovens quando há relacionamento entre temas científicos e crenças religiosas.

Os estudantes aceitam itens que afirmam sobre os registros fósseis como provas da existência de espécies que viveram no passado: $54,6 \%$ concordam com a afirmação Os fósseis são indícios de espécies que viveram no passado e que estão extintas hoje em dia). Eles também concordam com a seleção natural: 60,3\% entendem que se um ser vivo pode viver bem em um ambiente, poderá ter muitos descendentes com as características vantajosas. Já quando o item tratava-se da ancestralidade comum, houve menor aceitação entre os estudantes: $52 \%$ discordam de que diferentes espécies podem possuir uma mesma espécie ancestral.

Sobre a atribuição de fenômenos naturais para explicar a origem e a evolução da Terra, 50,2\% concordam que isso seja possível. No entanto, a concordância é menor

* Os destaques em itálico remetem às questões de número 6 da sessão 3; questões 2, 6, 10, 7, 9, 8 da sessão 4, dispostas no questionário aplicado aos informantes. 
quando as afirmações se voltam para a origem e evolução humana, com um índice de $44,5 \%$ de aceitação para a afirmação $O$ ser humano se originou da mesma forma como as demais espécies biológicas; 49,3\% para A espécie humana habita a Terra há cerca de 100.000 anos; e 35,2\% para Primeiros humanos viveram no ambiente africano. Destacam-se os percentuais de "não resposta" de 14,1\% também para os itens relacionados à origem e evolução humana.

Embora sejam menores os níveis de concordância dos estudantes com itens sobre a origem e evolução humana, não houve diferença significativa ( $5 \%$ ) entre as respostas. Esses resultados apontam que os estudantes parecem interessados e motivados por temas relacionados à teoria da Evolução Biológica.

Essa motivação não parece influenciada por uma proximidade com a religião, pois a maioria dos jovens se considera religioso e acredita em explicações teológicas para origem da vida, como pode ser observado nos níveis de aceitação dos itens das questões Sou uma pessoa religiosa**, em que $76 \%$ concordam; em Acredito na doutrina ou nos ensinos religiosos, com 70,4\% de concordância; em Os conhecimentos religiosos são úteis no meu dia a dia, com 69,6\% de concordância; e em Acredito nas explicações religiosas para origem da vida, com o qual $72 \%$ concordam. Portanto, existe uma aparente convivência de ideias opostas para o jovem estudante.

Esses resultados contradizem os dados encontrados por Oliveira e Bizzo[8], que pesquisou sobre esses mesmos temas dentre estudantes do ensino médio de Tangará da Serra (MT) e São Caetano do Sul (SP). Os resultados do pesquisador mostram que os níveis de aceitação parecem influenciados principalmente pela religião: os estudantes mato-grossenses e evangélicos apresentaram níveis mais baixos de concordância com a teoria evolutiva, diferentemente dos estudantes paulistas, que apresentam níveis mais altos de aceitação, inclusive de itens referentes à origem e evolução da Terra e do ser humano.

Contudo, Bizzo, Santos Gown e Mota [4], em uma pesquisa semelhante que realizaram em âmbito nacional, não encontraram relações de proximidade dos jovens em relação à teoria da evolução e crenças religiosas, e destacam que a aceitação da evolução não varia consideravelmente entre os sexos e entre as religiões, embora as meninas, de maneira geral, e os meninos evangélicos mostrem menor concordância com essa ideia do que meninos e meninas católicos. Um resultado relevante, apontado pelos autores, foi a discordância de $80 \%$ dos católicos e de $67 \%$ dos evangélicos com a afirmação minha religião me impede de acreditar na evolução biológica.

Diante dos resultados apresentados, os autores citados comentam que os jovens parecem entender que a ciência não pode ser vista como um simples sistema de verdades e dogmas, e que a religião não impede o desenvolvimento de nossa capacidade de observar e interpretar o mundo.

Assim, considerando os resultados encontrados por Bizzo, Santos Gouw e Mota [4] e os apontados na pesquisa apresentada neste artigo, surgem novos questionamentos,

\footnotetext{
** Os destaques em itálico remetem às questões de número $1,2,5,6$ da sessão 2 , dispostas no questionário aplicado aos informantes.
} 
pois se os jovens parecem capazes de negociar suas crenças religiosas e científicas sobre a origem da Terra e da vida, quais seriam as estratégias utilizadas por esses jovens para negociar a ciência e religião como campos independentes?

Nas respostas dos professores aparecem algumas tendências semelhantes às percepções dos estudantes. Quanto à proximidade com as religiões, 13 professores se consideram pessoas de fé; oito deles julgam compreender os ensinamentos religiosos; 14 consideram que os ensinamentos religiosos são uteis no seu cotidiano; e 10 concordam que religião deve ser ensinada na escola.

Sepúlveda e El-Hani [13] argumentam que é possível uma convivência pacífica, no pensamento individual, entre crenças pessoais e ciência, desde que elas coexistam em contextos diferentes. Os dados analisados mostram que os professores pesquisados acreditam nas evidências científicas para explicar a origem e evolução da vida e, a parte majoritária não concorda com os relatos bíblicos sobre a criação. Dentre os professores, oito concordaram que é possível conciliar a teoria da Evolução Biológica com explicações religiosas e culturais para origem e evolução humana.

Todos os professores concordaram totalmente com os tópicos relacionados à teoria da evolução biológica, sendo que apenas um professor não concorda que os primeiros humanos tenham vivido em ambiente africano.

Quanto ao ensino da evolução biológica, os professores consideram de grande importância para o ensino básico, mas embora tenham estudado essa teoria durante a graduação, 13 professores afirmaram não terem sido preparados para trabalhar em sala de aula as questões socioculturais que influenciam a aprendizagem desse tema pelos estudantes.

Também foi consenso, entre os professores, que a formação cultural dos alunos da educação básica influencia na compreensão dos conceitos-chave da teoria da Evolução Biológica, e consideram que conhecem poucos caminhos e estratégias pedagógicas que amenizem os conflitos entre a religião e a ciência em sala de aula.

Asghar, Wiles e Alters [2], ao estudarem os sentimentos e preocupações de futuros professores canadenses quanto à abordagem do tema da evolução biológica no ensino fundamental, explicam que esses docentes aceitam a teoria da evolução biológica e que pretendem incluir o ensino do tema no currículo de ciências. No entanto, existe entre os professores a preocupação com a aceitação da teoria por parte dos estudantes e seus pais, já que a inclusão desse tema nas aulas de ciências pode se confrontar com as crenças religiosas dos estudantes. Outro ponto que preocupa esses futuros docentes, segundo os estudos desses autores, é a impressão de que a formação acadêmica não contribuiu com a compreensão adequada da teoria, além de não oferecer embasamento teórico sobre estratégias pedagógicas para trabalhar com temas controversos em sala de aula.

Na pesquisa a que se refere este artigo, os professores também concordam com a inclusão do ensino de questões religiosas na escola, ao mesmo tempo reconhecem que seus alunos apresentam dificuldades de compreensão da teoria da evolução biológica devido a influências socioculturais. Portanto, é necessário refletir e aprofundar mais os estudos sobre como esses profissionais poderiam intermediar 
suas crenças pessoais, as questões religiosas ensinadas na escola e ainda o ensino da teoria da evolução biológica.

De maneira geral, os dados analisados apontam que as percepções positivas em relação à ciência e à teoria da evolução biológica foram comuns entre os estudantes e professores, e que questões religiosas não parecem influenciar explicitamente nas suas opiniões e posicionamentos. No entanto, considera-se necessário o desenvolvimento de estudos de cunho quantitativo associados a qualitativos para aprofundar a compreensão de como as características culturais e sociais dos sujeitos pesquisados se relacionam com a percepção da ciência.

\section{OFICINAS PEDAGOGGICAS NA ESCOLA: CONCILIANDO A FORMAÇÃO ACADÊMICA COM A DIVULGAÇÃO CIENTÍFICA}

O estudo das percepções de estudantes e professores forneceu subsídios para a definição do que, para quem e como comunicar temas científicos. Como exemplo, cita-se a preocupação que os professores inquiridos apresentaram com a influência das crenças religiosas dos estudantes na aprendizagem da teoria da evolução biológica. Por outro lado, esses jovens apresentaram percepções positivas com relação à evolução biológica, independentemente de suas afiliações e proximidade com a religião.

Os programas de extensão articulados com ensino e pesquisa contribuem para aproximar a universidade das demandas da comunidade, e essas propostas de aproximação incidem, em primeiro lugar, a dar voz a todos os participantes dessa comunidade. As atividades de extensão e pesquisa na escola precisam ser compreendidas a partir da participação ativa de pesquisadores e dos sujeitos da escola, por isso, antes de qualquer definição pedagógica para a pesquisa apresentada neste artigo, foi realizada uma escuta de professores e alunos.

Assim, as oficinas foram elaboradas pelos acadêmicos considerando essas intenções mais abrangentes de comunicação, favorecendo a proximidade dos estudantes do ensino básico a temas científicos, sob uma ótica mais crítica de seus benefícios e processos.

Para elaboração das oficinas, os licenciandos buscaram referenciais teóricos específicos da biologia e da educação, conciliando os dois campos de conhecimento. No entanto, ao longo das elaborações das atividades das oficinas percebeu-se uma forte tendência entre os graduandos por estratégias de mera transmissão do conhecimento, em geral, criticadas pelos eles próprios. Percebe-se, portanto, que ao definirem suas estratégias pedagógicas, esses alunos de licenciatura ainda possuem dificuldades de implementarem situações didáticas em que os estudantes da educação básica tenham papel mais ativo em sala de aula.

De acordo com Vogt [15] quando iniciativas de comunicação e ensino de temas científicos são elaboradas pela comunidade acadêmica e executadas no âmbito do ensino básico, existe uma forte tendência de reduzir à comunicação científica a transferência de conhecimentos, o que "frequentemente produz o contrário da intenção inicial: aproximar, compartilhar e estimular”. 
No entanto, a partir do diálogo entre professores-formadores, alunos de licenciatura e sujeitos da escola, à luz de referenciais teóricos da educação e específicos da biologia, as concepções prévias de ensino e o papel do professor e aluno em sala de aula podem ser analisados criticamente, como ocorreu no projeto apresentado neste artigo, possibilitando novas formas de se concretizar o ensino de temas científicos.

Desde o planejamento das atividades das oficinas pedagógicas, os alunos de licenciatura retomavam suas concepções de ensino e aprendizagem de temas científicos, reformulando os saberes teóricos e as possibilidades reais da prática na escola. Além disso, ao transpor para o conhecimento escolar o conhecimento acadêmico sobre a teoria da evolução biológica, os alunos analisaram suas próprias percepções e conhecimento sobre a teoria e as ideias de Darwin sobre seleção natural e dinâmica do meio ambiente.

As oficinas foram oferecidas em um dia letivo para cada escola. Para inscrição dos estudantes do ensino médio, foi encaminhado um informativo sobre as oficinas e os alunos escolheram a que lhes pareceu mais atrativa.

Durante a criação de cada oficina, após os ajustes metodológicos de rompimento com a tendência às atividades tradicionais, os graduandos buscaram por atividades mais interativas, como: resolução de problemas, experimentos, demonstração de experimentos, exposição de documentários e filmes seguidos de debates, dentre outras atividades que buscavam relacionar concepções científicas e cotidianas sobre a evolução biológica.

As oficinas contaram com 192 participantes e, para atender a todos, algumas foram oferecidas em mais de um turno. Em cada oficina, os ministrantes criaram estratégias para conhecer as concepções prévias dos alunos do ensino médio, e ao final, estes responderam uma avaliação sobre o curso.

Todas as oficinas foram bem avaliadas pelos estudantes, que demonstraram motivação e interesse em participar das atividades elaboradas, atendendo, assim, às expectativas de todos os envolvidos. Para exemplificar os resultados positivos alcançados, será apresentada, a seguir, a oficina Os fósseis e você, tudo a ver.

Considerando, que a paleontologia apresenta conceitos fundamentais para compreensão de fenômenos naturais e da história do planeta Terra, bem como sustenta a teoria da evolução biológica, além de ter sido um importante componente para formulação da Origem das Espécies, de Charles Darwin, alguns graduandos optaram pelo desenvolvimento de uma oficina sobre o tema.

Para as atividades propostas, foram desenvolvidos os seguintes materiais: um jogo de tabuleiro para identificação de concepções prévias; atividades práticas que demonstravam como ocorre o processo de fossilização; e exposição de imagens de fósseis encontrados no mundo e, principalmente, no Brasil. Por fim, os graduandos propuseram uma discussão sobre como são feitos os estudos com fósseis e sua importância para a compreensão da origem e evolução dos seres vivos, apresentando também conhecimentos sobre a idade da Terra e registros fósseis nos estudos desenvolvidos por Darwin.

A oficina foi oferecida para estudantes do $1^{\circ}$ ano do ensino médio, em dois turnos com turmas de 20 alunos cada. Inicialmente, os alunos foram divididos em pequenos 
grupos e desafiados por um jogo de perguntas e respostas, o Jogo dos Fósseis, que consiste em um tabuleiro que identifica concepções prévias dos estudantes sobre o tema. Ao longo da atividade, os ministrantes anotavam as principais respostas dos grupos e, após analisarem-nas, identificaram que a maioria das ideias sobre fósseis estava associada a restos de dinossauros e, principalmente, que a fonte de informação desses estudantes era a mídia, em programas de televisão e internet.

Em seguida, esses alunos foram convidados a confeccionar alguns moldes de fósseis, através do uso de massa de modelar e gesso, possibilitando a reflexão sobre como ocorre o processo de fossilização. Foram apresentados, previamente, alguns fósseis produzidos com gesso, simulando as formas reais e abordando com os alunos como este artefato seria conservado ao longo dos anos.

Novas informações sobre os fósseis eram agregadas às atividades gradualmente, por meio de exposições de imagens e da proposta de discussões a partir de textos disponíveis na revista Ciência Hoje, particularmente a coluna Caçadores de Fósseis. A utilização de textos de divulgação científica justifica-se pelo tempo disponível para oficina e por se tratar de um material já adaptado para o público escolar em geral. Ao longo da oficina, os ministrantes buscavam interfaces entre as dúvidas e comentários apresentados pelos estudantes e o conteúdo conceitual.

No final das atividades os estudantes do ensino médio responderam a uma pesquisa sobre o que foi estudado e avaliaram o curso por meio de um formulário composto das seguintes questões dissertativas: $\mathrm{O}$ que você aprendeu de novo hoje? O que é um fóssil? O que mais gostou na oficina? $\mathrm{O}$ que menos gostou na oficina? $\mathrm{O}$ que lhe despertou mais interesse hoje? O que você mais gostou do jogo? O que você mais gostou na construção dos fósseis?

Os estudantes pareceram satisfeitos com a oficina, demonstrando motivação em estudar e pesquisar mais a respeito do que foi apresentado suscitando novos interesses diante de temas científicos. Eles destacaram que aprenderam uma nova acepção para o termo "fóssil”, já que o tema não estava tão restrito aos dinossauros, ampliando seus conceitos, por exemplo, para fósseis de vegetais, o que não parecia possível anteriormente. Dentre os pontos negativos identificados pelos ministrantes destaca-se a organização/sequência das atividades em relação à dinâmica da sala de aula, e a carga horária disponível, que pareceu insuficiente para o que foi proposto.

As atividades de extensão em parceria com os sujeitos da escola retomam a discussão de que a formação inicial docente se coloca tanto no contexto universitário quanto na educação básica. Embora esse projeto desenvolvido tenha sido de curto prazo em sala de aula, construído a partir de ideias didáticas comuns e simples, a experiência de sua aplicação representou mais uma possibilidade de superação de um ensino fragmentado e desconectado da realidade do exercício docente.

No aprendizado a partir de situações concretas os alunos de licenciatura tiveram oportunidade de refletir sobre os conteúdos biológicos enquanto temas que deverão ser ensinados e transpostos para o saber escolar, contribuindo, assim, para o desenvolvimento da competência de selecionar, avaliar e refletir sobre as diferentes estratégias didáticas para ensinar temas científicos. Do outro lado, os professores e alunos da educação básica contemplados com as oficinas tiveram oportunidade de reconstruir a relação com a ciência e os temas científicos. 
Por fim, considera-se que iniciativas de desenvolvimento da cultura científica são indispensáveis para inclusão dos jovens na compreensão da vida cotidiana e nela atuar transformando a sua realidade e, principalmente, participando e julgando decisões políticas.

\section{REFERÊNCIAS}

[1] ALTERS, B. J.; ALTERS, S. M. Defending evolution in the classroom: a guide to the creation/evolution controversy. Canada: Jones and Bartlett Publishers, 2001.

[2] ASGHAR, A.; WILES, J. R.; ALTERS, B. Canadian pre-service elementary teacher's conceptions of biological evolution and evolution education. MCGILL Journal of Education n. 42(2), p. 189-210, 2007.

[3] BIZZO, N. Darwin: do telhado das Américas à teoria da Evolução. São Paulo: Ed. Odysseus, 2002.

[4] BIZZO, N.; SANTOS GOUW, A.; MOTA, H. S. Evolução e religião: o que pensam os jovens estudantes brasileiros. Ciência Hoje, v. 50, n. 300, p. 26-31, 2013.

[5] BROTAS, A. M. P. Jornalismo Científico em tempo de controvérsia. In: PORTO, C. M.; BROTAS, A. M. P.; BORTOLIERO, S. T. (Orgs.) Diálogos entre ciência e divulgação científica: leituras contemporâneas. Salvador: EDUFBA, 2011, p.123-152.

[6] COBERN, W. W. Point: Belief, Understanding, and the Teaching of Evolution. Journal of research in science teaching, v. 31, n. 5, p. 583-590, 1994.

[7] MEYR, D.; EL-HANI, C.N. Evolução: o sentido da Biologia. São Paulo: Editora UNESP, 2005.

[8] OLIVEIRA, G. S.; BIZZO, N. Aceitação da evolução biológica: atitudes de estudantes do ensino médio de duas regiões brasileiras. Revista Brasileira de Pesquisa em Educação em Ciências, v.11, n.o1, p. 57-79, 2011.

[9] PEREIRA, J. C. R. Análise de dados qualitativos: estratégias metodológicas para as ciências da saúde, humanas e sociais. $3^{\circ} \mathrm{ed}$. São Paulo: Editora da Universidade de São Paulo, 2001.

[10] SANTOS GOUW, A. M. As opiniões, interesses e atitudes dos jovens brasileiros frente à ciência: uma avaliação em âmbito nacional. 2013. Tese (Doutorado em Educação) - Faculdade de Educação, Universidade de São Paulo, São Paulo, 2013.

[11] SANTOS, S. C. Evolução Biológica: ensino e aprendizagem no cotidiano da sala de aula. São Paulo: Annablume; Fapesp: Pró-Reitoria de Pesquisa, 2002.

[12] SCHREINER, C.; SJØBERG, S. Empowered for action? How do young people relate to environmental challenges? In: ALSOP, S. (Ed.). Beyond Cartesian Dualism: Encountering affect in the teaching and learning of science. Dordrecht: Springer, 2005.

[13] SEPULVEDA, C. A. S. E.; EL-HANI, C. N. Quando visões de mundo se 
encontram: religião e Ciência na trajetória de formação de alunos protestantes de uma licenciatura em Ciências Biológicas. Investigaciones en Enseñanza de las Ciencias; Investigations in Science Education. v.09, n.02, 2004. Disponível em: < http://www.if.ufrgs.br/public/ensino/revista.htm>. Acesso em: 04 ago. de 2013.

[14] VOGT, C. A.; CASTELFRANCHI, Y. Interesse, informação e comunicação. Cultura científica em Iberoamérica encuesta em grandes núcleos urbanos. ed. 1, Fecyt, OEI, Ricyt, pp. 16, p.21-36, 2009.

[15] VOGT, C. A. Ciência, Comunicação e Cultura Científica. In: VOGT, C. (org.). Cultura Científica: desafios. São Paulo: Edusp/Fapesp, 2006, p.19-26.

GRACIELA DA SILVA OLIVEIRA docente do Instituto de Biociências da Universidade Federal do Mato Grosso (UFMT) e doutoranda da Faculdade de Educação da Universidade de São Paulo (FE-USP) -e-mail: graciela@usp.br 